\title{
ОСНОВЫ АНТРОПОЛОГИЧЕСКОЙ ЛИНГВОДИДАКТИКИ: ИСТОКИ, СОСТОЯНИЕ, ПЕРСПЕКТИВЫ
}

\section{ANTHROPOLOGICAL LINGUODIDACTICS: ORIGINS, STATUS, PROSPECTS}

L. Muhammad

Summary: The study is devoted to the emergence, formation and peculiarities of the development of Russian anthropological linguodidactics. The relevance of the study is conditioned by the need to comprehend and systematize the rich theoretical and practical experience of Russian humanistic (anthropological) linguodidactics and to determine the prospects for its development.

Keywords: Russian anthropological linguodidactics; pedagogical anthropology; basic principles

\author{
Мухаммад Людмила Петровна \\ Д.п.н., профессор, Московский государственный \\ лингвистический институт, Москва \\ ludmilamuh@mail.ru
}

Аннотация: Исследование посвящено возникновению, становлению и особенностям развития российской антропологической лингводидактики. Актуальность исследования обусловлена потребностью осмыслить и систематизировать богатый теоретический и практический опыт российской антропологической (гуманистически ориентированной) лингводидактики и определить перспективы её развития.

Ключевые слова: российская антропологическая лингводидактика; педагогическая антропология; базовые принципы.
A нтропологическая лингводидактика - относительно молодая наука, в задачи которой входит формирование инновационной, гуманистически ориентированной, системы обучения иностранным языкам (далее: ИЯ), в том числе и русскому языку как иностранному (РКИ), начиная с её высшего, методологического, уровня и заканчивая значимыми компонентами нижележащих уровней. И хотя мы определяем данную педагогическую науку как относительно молодую, тем не менее, хотели бы подчеркнуть, что она имеет весьма глубокие корни как в зарубежной, так и в российской философии, психологии, лингвистике, педагогике и лингводидактике.

Остановимся на чрезвычайной актуальности данной науки, и в особенности это касается нашего «железного века», где роль и значимость человеческого «я» вытесняется всё в большей и большей мере. В этих условиях, как не раз уже отмечалось на страницах социально значимой периодической печати, роль демократически ориентированных регуляторов взаимоотношений человека и общества, общества и «надстройки» должны сыграть университеты. И сохранение гуманистических традиций в университетах, и в иных общественных институтах, следует рассматривать не столько как цель/ задачи, а как весьма трудную, сложную, но настойчиво преображающую миссию сторонников педагогической антропологии, антропологической лингвистики, психологии, психолингвистики и лингводидактики в условиях сложившихся «стандартов» образования, и человеческих интеракций.

Теоретическая значимость данной работы нами видится в осмыслении и систематизации богатого теоретического и практического опыта российской антропологической (гуманистически ориентированной) педагогики, психологии и лингводидактики, а также в моделировании (на этой основе) настоящего и будущего в развитии антропологической лингводидактики и её роли в формировании приемлемых для человека субъект-субъектных взаимоотношений и взаимодействий в пространстве родной этнокультуры и социума, в межкультурной коммуникации и, как перспектива, в мировом коммуникативном пространстве. Всё вышесказанное демонстрирует и цель настоящей работы, которая, если формулировать кратко, состоит в определении системообразующих компонентов и признаков прежде всего российской антропологической лингводидактики. Определение именно этих компонентов и признаков позволит, во-первых, создать модель учебного субъектсубъектного взаимодействия на русском языке (далее: РЯ), во-вторых, сформировать на этой базе у иностранных учащихся умений общаться и решать коммуникативные задачи на РЯ не только в рамках академической среды, но и за её пределами, в обиходно-бытовой и социально-культурной сферах общения.

В самом начале изложения истории вопроса подчеркнём, что идеи человеколюбия, идеи доброго отношения к самому незащищённому человеку -учащемуся всегда занимали умы лучших общественных деятелей и педагогов России, к примеру, А.И. Герцена, К.Д. Ушинского, Н.Ф. Бунакова, П.Ф. Каптерева, В.А. Сухомлинского, А.А. Леонтьева и многих других [2; 4; 10]. Так, в своих работах А.И. Герцен писал, что «именно личность является основной ценностью... вне личности, без её участия в 
обществе невозможно никакое движение» [7, с. 177].

Через несколько лет после публикаций А.И. Герцена российская педагогическая наука получает в дар величайшее произведение педагогической мысли - «Педагогическую антропологию» К.Д. Ушинского, предметом которой и становится развивающаяся личность во всём её многообразии [2, с. 38 - 67].

По нашему мнению, величайшей заслугой в становлении антропологически значимой лингводидактики является научная, научно-экспериментальная и практическая деятельность выдающегося советского и российского учёного А.А. Леонтьева [10;11]. Именно А.А. Леонтьев подвёл под отечественную коммуникативнодеятельностную лингводидактику, в частности, методику преподавания ИЯ/РКИ, солидную психолингвистическую базу.

Именно А.А. Леонтьев первым обосновал необходимость строить процесс обучения неродному языку как процесс общения на данном языке, что, в контексте теории речевой деятельности (РД), позволило сформировать абсолютно новую парадигму данного процесса, центр которого составили: а) общение как деятельность; б) субъект-субъектная интеракция.

Как известно, на сегодняшний день сложилось несколько вариантов коммуникативно-деятельностных методик обучения РЯ иностранцев $[11 ; 12 ; 15]$. В данной работе в нашу задачу не входит анализ и дифференциация данных вариантов, однако, как нам представляется, выделить некий инвариант (общую часть разных вариантов), особенно для магистрантов, аспирантов и начинающих преподавателей, всё же необходимо. Начнём с методологии: высший, методологический, уровень данных методик представляют:

1. подход к обучению: коммуникативно-деятельностный (т.е. психолингвистическую основу данных методик составляет теория деятельности/ РД - со всеми её компонентами);

2. принципы обучения: психологические, лингвистические, общедидактические и собственно методические;

3. методы обучения: прежде всего сознательнопрактический, а также преображённый на основе теории деятельности коммуникативный методы. Последовательная и усложнённая система рассматриваемых методик весьма доходчиво охарактеризована в юбилейной «Методике преподавания русского языка как иностранного» О.Д. Митрофановой, В.Г. Костомарова, М.Н. Вятютнева, Е.М. Степановой, Э.Ю. Сосенко как «коммуникативно-деятельностная основа обучения» (выделено нами). Данная основа включает в себя простые и сложные учебные действия, на вер- бальном уровне представленные коммуникативными единицами - высказыванием и текстом, а также способами оперирования данным материалом - учебными речевыми действиями, дифференцированными по разным признакам, например, а) устная речь (говорение/аудирование); б) письменная речь (чтение/письмо) [12].

Далее попытаемся раскрыть сущность варианта, предложенного А.А. Леонтьевым в его более поздних работах, поскольку именно данная вариативная методика положила начало современной антропологической лингводидактике.

Как известно, А.А. Леонтьев постоянно, последовательно и неутомимо в своих работах отстаивал именно коммуникативно-деятельностную методику (в противовес коммуникативно-поведенческой). В его более позднем варианте в качестве центрального представлен феномен общения, при котором системообразующая роль отводится личности (личности учащегося) как субъекту этого общения [10;11]. Причём к личности учёный относится как к целостному образованию (т.е. в традиции отечественной философской и педагогической антропологии) [2;4;7;10]. Таким образом, в ситуации отстаивания личности как целостного образования и центра образовательных систем рождается весьма значимый в коммуникативно-деятельностном направлении преподавания ИЯ/РКИ вариант этого направления - вариант, базирующийся на личностно-деятельностной модели обучения.

В заданном контексте следует отметить несколько важных отличий личностно-деятельностных методик от иных вариантов коммуникативно-деятельностного обучения. Так, нам представляется заслуживающими внимания психолого-педагогические концепции И.А. Зимней и Г.А. Китайгородской, - также придерживающихся и разрабатывающих основы личностно-деятельностного подхода к обучению. Работы И.А. Зимней, как известно, положили начало последовательному включению в учебный процесс когнитивного принципа [5].

Для развития моделей антропологической лингводидактики весьма перспективна также и педагогическая стратегия Г.А. Китайгородской, в основе которой лежат техники актуализации и включения в РД резервных возможностей личности учащегося [9].

Таким образом, на основании анализа базовых компонентов лично-деятельностных моделей обучения мы праве сделать вывод о том, что в основе данных моделей (а, следовательно, и учебного процесса, реализуемого по данным моделям) лежит известный в философии педагогики и педагогической антропологии базовый принцип современных гуманитарных наук - антропологиче- 
ский принцип [13;14]. И это именно тот принцип, который позволяет квалифицировать антропологическую лингводидактику как гуманистически ориентированную науку, наследницу предшествующих лингводидактических наук, у основания которых лежит лично-деятельностный подход к обучению.

Ниже попытаемся выделить также и иные дифференцирующие признаки, которые отличают антропологическую лингводидактику от иных коммуникативно-деятельностных вариантов (далее для удобства назовём эти вариативные методики традиционными).

Как известно, традиционные коммуникативно-деятельностные методики преподавания ИЯ/РКИ при моделировании учебного процесса (по крайней меретеоретически) ориентируется на коммуникативные потребности личности учащегося. Модели же антропологической лингводидактики сориентированы прежде всего на экзистенциальные (жизненно важные) потребности личности учащегося (в которые включены, в том числе, и его коммуникативные потребности). Наши исследования экзистенциальных потребностей личности учащегося (при составлении карты достижений будущего профессионала) показывают, что к экзистенциальным потребностям личности иностранного учащегося, изучающего РЯ в условиях России относятся: потребность в росте и развитии, потребность в получении образования (прежде всего образования, направленного на будущую профессию), потребность в общении, потребность в самоидентификации и самоактуализации, потребность в пространстве, где можно уединиться (в целях самообразования и творчества). Следует подчеркнуть, что на определенном этапе обучения (временной отрезок этого этапа у каждого проявляется по-своему) на первое место выходит у иностранных учащихся потребность именно в успешном овладении будущей профессией.

Подчеркнём, что конституирующим признаком учебного процесса, организованного по моделям и педагогической антропологии, и антропологической лингводидактики, является эвристичнось [2; 10; 16]. Эвристичность учебного общения обязывает и личность преподавателя, и личность учащегося быть гибкими и открытыми к разнообразным вариантам развёртывания коммуникации - контактного и дистантного общения. А это, в свою очередь, требует от участников коммуникативных актов чёткого понимания: а) задач общения (и умений решать эти задачи); б) хорошо развитой когнитивной системы, обеспечивающей данное общение. В связи со сказанным, кроме антропологического принципа, в качестве базовых принципов антропологической лингводидактики выделяются коммуникативный и когнитивный принципы. Первый из этих принципов уже изначально заложен в коммуникативных методиках (о чём мы писали выше), феномен когнитивного принципа в силу различного его понимания на современном этапе требует некоторого объяснения.

С реализацией когнитивного принципа в антропологической лингводидактике прежде всего связывается пошаговое формирование у учащегося необходимой структурированной пресуппозиции, обеспечивающей коммуникативное взаимодействие как в условиях аудитории, так и за её пределами. По нашему мнению, в качестве первичной задачи по реализации когнитивного принципа является задача организации учебного общения на РЯ, в наибольшей степени соотносящегося с когнитивно-речевыми особенностями личности иностранного учащегося. В рассматриваемом контексте это, естественно, означает, что центр национальной языковой личности (ЯЛ) иностранного учащегося заполнен, естественно, содержанием и структурами родной этнокультуры со всеми её как статическими, так и динамическими характеристиками, в том числе и информационными. А это прежде всего значит, что оптимальные методики - это методики, опирающиеся на данный центр, на его потенциал в деле обучения общению на ИЯ/РКИ. И такая педагогическая стратегия, опирающаяся на эту сильную, животворящую, сторону личности, существенно отличается от того, что предлагает большая часть привычных нам методик. К примеру, во многих из даруемых молодёжи (молодым преподавателям) теоретических методик отсутствует не только национальная языковая личность (ЯЛ), но и личность учащегося вообще. Данные методики исходят из большого количества самых разнообразных принципов, как, например, из 27 принципов (!), изложенных в классических методиках преподавания РКИ [15, с. 232], однако за этими принципами теряется сама личность - центр управления своими состояниями и взаимодействиями.

Касаясь более тонких отличий антропологической лингводидактики от традиционной, обратим внимание, что реализация когнитивного принципа, согласно концепции антропологической лингводидактики, предполагает опору на инвариантное содержание контактирующих при обучении языков: родного языка учащихся и изучаемого, РЯ. В качестве такого инварианта выделяется семантический компонент - общий для двух контактирующих языков [3]. Так, включение в учебное общение китайских учащихся форм творительного падежа (Т.п.) следует производить на инвариантном семантическом компоненте «комитатив» (совместность действия), поскольку и в РЯ, и в китайском языке имеется союз «и»: Ср. рус.: 1) «Я и сестра - обедаем». В китайском языке имеется аналогичная структура с сочинительным союзом «и». Далее, опираясь на актуализированный семантический компонент и, таким образом, подготовив учащегося к восприятию синонимичной (по содержанию) конструкции, допустимо представить обозначенное содержание 
и в иной конструкции: 2) «Я с сестрой обедаю»; вариант 2а) «Я обедаю с сестрой». Здесь можно объяснить студентам, что в РЯ и 1, и 2 (и 2а) - фразы-синонимы, обозначающие одно и то же пропозициональное содержание. И только затем, на вполне определённом этапе усвоенности учащимися русскоязычных вербализаций «совместности» можно дать им Т.п. в значении орудия действия: «Я пишу ручкой». Как показывает практика, при такой методике инвариантная (универсальная) функция Т.п. РЯ оказывается для учащегося-китайца намного понятнее и, следовательно, запоминается лучше.

К сказанному выше добавим: традиционные методики с их собственно методическим принципом «учёт родного языка учащегося» предлагают, как видим, собственно учёт, т.е. первую стадию работы над ошибками, однако как этот «учёт» использовать далее - в традиционных методиках (реализующих принцип «учёта...») не предлагается, здесь каждый из преподавателей решает этот вопрос по-своему (кто-то работает над ошибками уже «постфактум», а кто-то вообще их не исправляет).

В аспекте экзистенциальных потребностей учащихся хотелось бы также обратить внимание ещё на некоторые отрицательные тенденции, складывающиеся в наши дни как в теоретической, так и в практической лингводидактике, в частности, в методике преподавания ИЯ/РКИ. Во-первых, бездумное и далеко не безобидное употребление некоторых терминов, в своём потенциале несущих беды развивающейся в «заданном» учебном процессе личности. К таким терминам мы прежде всего относим термины «вторичная языковая личность» и «адаnтация личности». Понятно, что имея дело с языком, с процессами усвоения личностью неродного языка в коммуникативных целях, современная лингводидактика [1], вслед за лингвистикой [8], вправе опираться на термин языковая личность (ЯЛ). При этом рост, развитие личности в условиях учебного процесса по усвоению языка (где это усвоение является главной целью организуемого процесса) может маркироваться усваиваемыми личностью языковыми единицами. В этих условиях лингвистическое понятие ЯЛ для методик является вполне целесообразным. Приемлемым же для антропологической лингводидактики данное понятие может быть только при одном условии: если личность здесь понимается как целостное образование, как центр, управляющий своими действиями и взаимодействиями, в том числе и речевыми действиями с востребованными для определённой ситуации вербальными и невербальными средствами общения. Именно за это (за субъектность Личности) всегда в своих работах боролся выдающийся советский и российский психолог, психолингвист, филолог и лингводидакт А.А. Леонтьев [10]. В обозначенном контексте употребляемый в настоящее время лингвистический термин «вторичная языковая личность» [8] является для лингводидактики не просто бесполезным, но и весьма вредным, разрушительным в отношении личности учащегося. Если термин «вторичная языковая личность» для лингвистов носит вспомогательный характер, в исследовательских целях фиксирующий факт расслоения личности на первичную и вторичную, то у методиста совершенно иная, конструкторская, созидающая, цель: он призван воспитать, сформировать целостную личность/ЯЛ с единым центром управления своими состояниями и коммуникативными действиями/ деятельностью. Манипулирование в теоретических (а вслед и практических) методиках понятием «вторичная языковая личность» $[1$, с. 56] ведёт к весьма плачевному результату - к раздвоению личности, к явлениям, когда правое полушарие хранит в памяти картины родного этноса, воспринятого в детстве, а левое - выстраивает «с нуля» картину мира (в том числе и картину детства), усваиваемую с помощью изучаемого ИЯ/РКИ. Такая методика всегда ведёт личность к ощущению своей ущербности в стране изучаемого языка, поскольку в ней, в данной методике, исключена прочная связь - тот общий мостик, то универсально-уникальное детство, на котором зиждется вся дальнейшая жизнь двух культур, двух языков - родного и изучаемого - иностранного, объединённых, или сознательно разведённых теоретиками и практиками лингводидактической науки.

Ещё большую ущербность может почувствовать иностранец в стране изучаемого языка, если к нему применяют методику адаптации. Весьма наглядно представить данную методику и оценить её «враждебность» по отношению к личности можно на примере текста. Вот у нас есть весьма замечательный художественный текст, хватающий читателя, как говорится, за живое. А методист в целях включения данного текста в учебный процесс убрал из текста некоторые метафоры, слова, передающие глубокие смыслы... иными словами, адаптировал данный текст якобы «для удобства его прочтения»... Лучшие современные методики даже текст отказываются адаптировать, чтоб не потерять его смыслы, а худшие - тратят неимоверные усилия, чтобы адаптировать, сделать удобным, - человека, учащегося...

Всё вышесказанное - это примеры пагубных для развития личности учащегося теоретических моделей, рано или поздно переходящих в практику.

Ниже попытаемся обобщить всё ранее сказанное.

Итак, методологический уровень модели обучения (и реализующего её учебного процесса), соответствующий главным постулатам антропологической лингводидактики, задаёт парадигму её развёртывания следующим образом:

1. личностно-деятельностный подход к обучению;

2. антропологический, коммуникативный и ког- 
нитивный принципы, реализующие базовый подход и определяющие систему обучения, её содержание и способы оперирования данным содержанием;

3. ориентированность обучающей системы на реальное (а не декларативное) субъект-субъектное коммуникативное взаимодействие, В центре которого находится, с одной стороны, личность учащегося, изучающего ИЯ/РКИ и культуру изучаемого языка, с другой - личность преподавателя. При этом преподавателю необходимо принимать во внимание национальную ЯЛ учащегося с его экзистенциальными потребностями и личностными, этнокультурно и индивидуально обусловленными, возможностями;

4. ориентированность на воссоздание и создание коммуникативного пространства, индуцирующего, пробуждающего в личности учащегося всё наилучшее, что в нём заложено природой и процессами его творческой жизнедеятельности;

5. ориентированность на будущую профессию учащегося как одну из главных составляющих его экзистенциальных потребностей.

Таким образом, в центре учебного процесса, построенного по моделям антропологической лингводидактики, находится не просто личность учащегося, а личность в её динамическом аспекте - в аспекте роста и развития. Движущей силой данного роста и развития становится сама личность - субъект своих действий и взаимодействий. Мотивирующим фактором при этом являются экзистенциональные (жизненно важные) потребности личности (а не только коммуникативные). К наиболее важным из них относятся: потребность в росте и развитии, потребность в получении профессионально значимого образования, потребность в общении и уединении, потребность в самоидентификации и самоак- туализации, потребность в коммуникативно значимом пространстве, потребность в интеграции в новую для учащихся страну с её уникальной историей, культурой и языком [16].

Перспектива современной антропологической лингводидактики состоит:

В изучении современных программ, учебников и учебных пособий с позиции выработанных принципов, требований и, самое главное, экзистенциальных потребностей личности обучающегося.

В определении причин перегруженности содержания обучения.

В создании оптимальных моделей и педагогических стратегий обучения, формирующих базовые знания, умения и навыки, обеспечивающие учебную деятельность, в том числе и в профессиональном аспекте.

В актуализации механизмов субъект-субъектного общения, в том числе и в условиях самообразования, направленных на удовлетворение экзистенциальных потребностей личности учащегося.

В интегрировании в намеченную модель: 1) современных методик инклюзивного образования; 2) методик эксклюзивного образования.

Итак, на современном этапе, в наш весьма «затехнологизированный» век с признанием значимости билингвизма (и даже полилингвизма) [6] именно антропологическая лингводидактика имеет высокий шанс сохранить в мире человеческое «я» и вместе с ним человеческие отношения и человечность как высочайшее качество мировых цивилизаций.

\section{ЛИТЕРАТУРА}

1. Азимов Э.Г., Щукин А.Н. Словарь методических терминов. Санкт-Петербург: Златоуст, 1999.

2. Антология педагогической мысли России второй половины XIX - начала XX в./Сост. П.А. Лебедев. М.: Педагогика, 1990. - 608 с.

3. Васюхно Л.П. Учет катафорической функции падежной формы при обучении чтению студентов-нефилологов: дис. к. п. н. М., 1996. - 266 с.

4. Герцен А.И. Собр. соч. 1954. Т.3. - С. 77 - 246, Т. 20, с. $439-441$.

5. Зимняя И.А. Психология обучения неродному языку (на материале русского языка как иностранного). — М., 1989. — 220 c.

6. Ипполитова Л.В., Чубарова 0.Э. Подходы к организации обучения русскому языку билингвов в российских вузах. Динамика языковых и культурных процессов в современной России. 2006. №5. - С. 1811 - 1816.

7. История русской философии: учебник/Под ред. М.А. Маслина. - Изд. 2-е. М.: КДУ, 2008. - 638 [2] с.

8. Караулов Ю.Н. Русский язык и языковая личность. М, 1987. - 261 с.

9. Китайгородская Г.А. Интенсивное обучение иностранным языкам. Теория и практика. М.: Рус. яз., 1992. - 255 с.

10. Леонтьев А.А. Язык и речевая деятельность в общей и педагогической психологии: Избранные психологические труды. М.: Московский психолого-социальный институт; Воронеж: НПО «МОДЭК», 20016. - 448 с.

11. Методика. Заочный курс повышения квалификации филологов-русистов/ Под ред. А.А. Леонтьева. М.: Русский язык, 1988. - 280 с.

12. Митрофанова 0.Д., Костомаров В.Г., Вятютнев М.Н., Сосенко Э.Ю., Степанова Е.М. Методика преподавания русского языка как иностранного. М.: Русский 
язык, 1990. - 269 с.

13. Мухаммад Л.П., Мухаммад Х.И.А., Хетагурова Н.Н. К вопросу о методологии современных гуманитарных наук. Вестник МАПРЯЛ. 2006 г. №53. С. 31.

14. Ушинский К.Д. Избранные педагогические сочинения в 6 томах. - М, 1980. -229 с.

15. Щукин А.Н. Методика преподавания русского языка как иностранного: учебное пособие. - М.: ФЛИНТА, 2019. - 508 с.

16. Mukhammad L.P., Tatarinova N.V., Khaleeva 0.N. Modeling a methodology for teaching a foreign language on the principles of anthropological linguodidactics (initial stage of learning). National Academi of Managerial Staff of Culture and Arts Herald. 2019. №1. C. 115 -121.

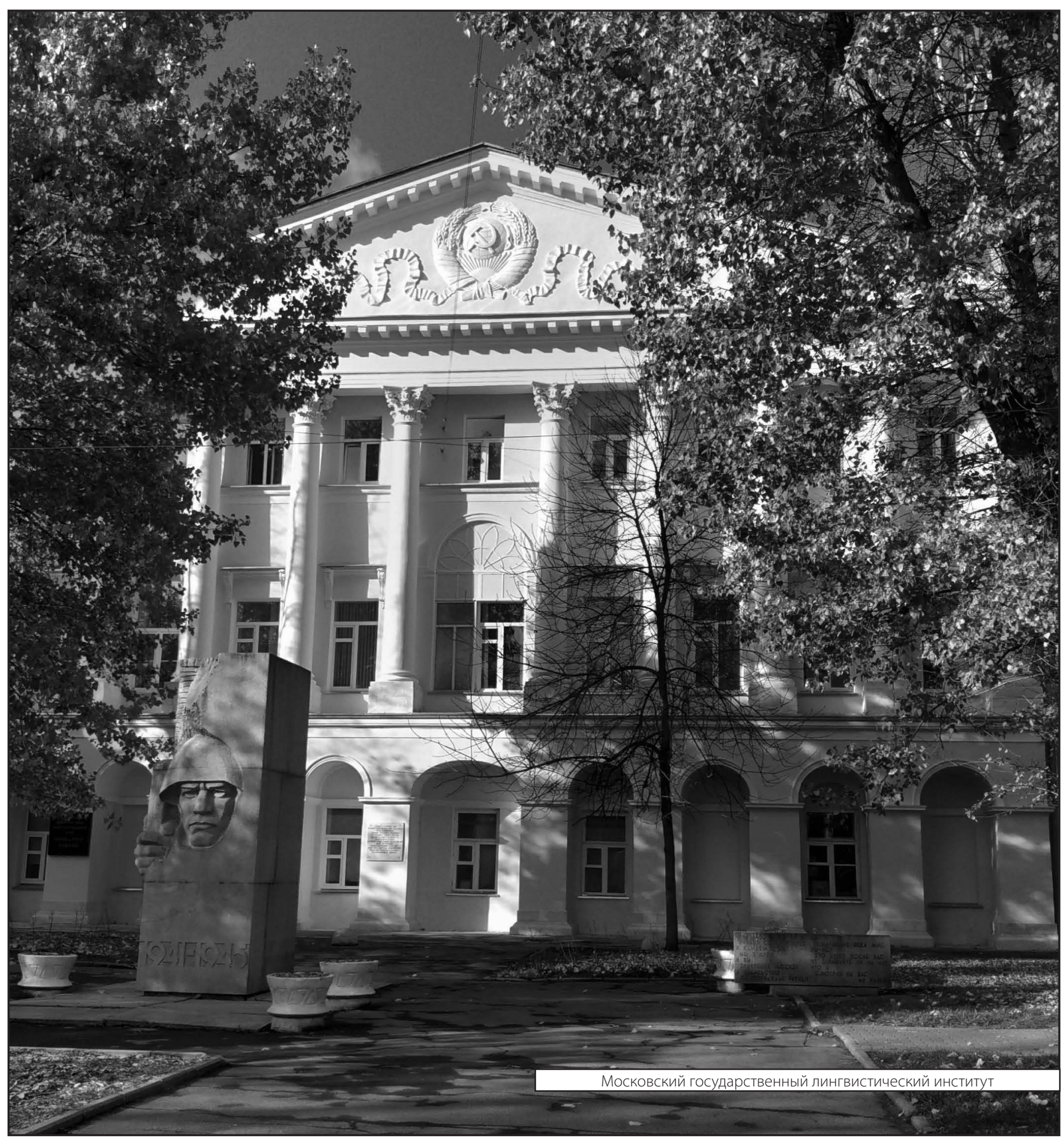

